\title{
The sonic hedgehog signaling pathway contributes to the development of salivary gland neoplasms regardless of perineural infiltration
}

\author{
Manuela Torres Andion Vidal $^{1}$ • Sílvia Vanessa Lourenço ${ }^{2}$. Fernando Augusto Soares ${ }^{2}$. \\ Clarissa Araújo Gurgel ${ }^{1} \cdot$ Eduardo J. B. Studart ${ }^{3} \cdot$ Ludmila de Faro Valverde $^{1}$ • \\ Iguaracyra Barreto de Oliveira Araújo ${ }^{1,3} \cdot$ Eduardo Antônio Gonçalves Ramos ${ }^{1}$. \\ Flávia Caló de Aquino Xavier ${ }^{4}$. Jean Nunes dos Santos ${ }^{1,4,5}$
}

Received: 9 November 2015 / Accepted: 12 January 2016/Published online: 21 January 2016

(C) International Society of Oncology and BioMarkers (ISOBM) 2016

\begin{abstract}
The pleomorphic adenoma (PA), mucoepidermoid carcinoma (MEC), and adenoid cystic carcinoma (ACC) are common tumors arising from salivary glands whose histopathology is heterogeneous. The sonic hedgehog signaling pathway $(\mathrm{Hh})$ and signal transducer and activator of transcription 3 (STAT3) play important roles in cell proliferation, favoring tumor growth. The aim of this investigation was to study components of the Hh pathway, as well as STAT3 in salivary gland neoplasms in an attempt to add information about the biological characteristics of these neoplasms. We used 9 cases of PA, 17 cases of ACC, and 20 cases of MEC. Using immunohistochemistry, SHH, GLI1, SUFU, HHIP, and STAT3 were investigated. For comparative purposes, MCM3 (cellular proliferation marker) was also included. In PA, there was high expression of cytoplasmic SHH and SUFU and low expression of STAT3 and MCM3. In the ACC, there was high expression of GLI1, HHIP, and STAT3 and low expression of SHH, SUFU, and MCM3. In the MEC, we observed high expression of SHH, GLI1, SUFU, and HHIP and low expression of
\end{abstract}

Jean Nunes dos Santos

jeanunes@ufba.br

1 Postgraduate Program in Human Pathology, Oswaldo Cruz Foundation, Salvador, Bahia, Brazil

2 A.C. Camargo Cancer Center, São Paulo, Brazil

3 Department of Pathology and Forensic Medicine, School of Medicine, Federal University of Bahia, Salvador, Bahia, Brazil

4 Laboratory of Oral Surgical Pathology, School of Dentistry, Federal University of Bahia, Salvador, Bahia, Brazil

5 Laboratório de Patologia Cirúrgica, UFBA, Avenida Araújo Pinho, 62, Canela, Salvador, Bahia, Brazil 40110-150
STAT3 and MCM3. There was a statistically significant difference between SHH $(p=0.0064)$, STAT3 $(p=0.0003)$, and MCM3 $(p=0.0257)$ when all tumors were compared and a higher expression in parenchyma for all tumors when stroma and parenchyma were compared $(p<0.05)$. These findings suggests a possible role of Hh pathway in the development and maintenance of the cytoarchitectural pattern of PA, ACC, and MEC, as well as the participation of STAT3 in the development of ACC, irrespective perineural infiltration.

Keywords Salivary gland tumors $\cdot$ Hedgehog proteins $\cdot$ STAT transcription factors $\cdot$ Minichromosome maintenance complex component 3

\section{Introduction}

Salivary gland neoplasms represent a heterogeneous group of tumors, as they present several histological types and distinct biological behaviors [1-3]. Pleomorphic adenoma (PA), mucoepidermoid carcinoma (MEC), and adenoid cystic carcinoma (ACC) are common tumors derived from the salivary gland [4-6], with ACC standing out for its capacity to invade the perineural space [7]. In addition, several studies have focused on predicting the course of these tumors.

The sonic hedgehog $(\mathrm{Hh})$ signaling pathway plays important functions in embryonic development and cell proliferation and differentiation [8-12]. Sonic hedgehog (SHH) is a ligand protein in the Hh signaling pathway, which, when secreted, binds to the Patched (PTCH) receptor, inactivating its inhibitory effect on the Smoothened (SMO) transmembrane protein. SMO, in turn, induces the activation of the gliomaassociated oncogene (GLI) family of transcription factors, 
Table 1 Antibody, label, clone, dilution, antigen retrieval, and positive control

\begin{tabular}{llllll}
\hline Antibody & Label & Clone & Dilution & Antigen retrieval & Positive control \\
\hline Anti-SHH & Novus Biologicals & $5 \mathrm{H} 4$ & $1: 1000$ & Citrate pH 6.0 & Placenta \\
Anti-HHIP & Sigma & Polyclonal & $1: 200$ & Citrate pH 6.0 & Placenta \\
Anti-GLI1 & Novus Biologicals & Polyclonal & $1: 600$ & Citrate pH 6.0 & Placenta \\
Anti-SUFU & Santa Cruz & Polyclonal & $1: 100$ & Citrate pH 6.0 & Placenta \\
Anti-STAT3 & Santa Cruz & F-2 & $1: 100$ & Citrate pH 6.0 & Lung carcinoma \\
Anti-MCM3 & Dako & 101 & $1: 50$ & EDTA pH 9.0 & Breast carcinoma \\
\hline
\end{tabular}

which regulate proliferation, differentiation, and interactions with the extracellular matrix [9, 13-16]. However, this pathway is controlled by two different antagonists including hedgehogInteracting Protein (HHIP) and Suppressor of Fused (SUFU); the hhip protein is a membrane glycoprotein with high binding affinity to ligands of the Hh pathway [17, 18], whereas sufu binds to GLI proteins, negatively controlling their activity through two mechanisms: sequestering GLI in the cytoplasm or inhibiting GL1 transcriptional activity [19-21]. Moreover, aberrant activation of the Hh pathway has been identified in various neoplasms, including hematological tumors [22] and carcinomas of the breast [23], stomach [24], esophagus [25], mouth [26], pancreas [27], liver [10], prostate [28], and thyroid [29].

Signal transducer and activator of transcription (STAT) is a family of transcription factors that remain latent when localized in the cytoplasm and is activated via phosphorylation
[30]. A high number of malignant neoplasms have constitutively active STAT proteins, more frequently STAT3 [31-35]. Constitutive STAT3 activation may increase cell proliferation and can lead to cell transformation, favoring tumor development [36-39].

It is known that aberrant activation of the Hh pathway has been identified in several neoplasms [23-25, 27, 29, 40], along with STAT3, as it plays relevant functions in tumor development $[22,36,38,41]$. Nonetheless, considering that to our knowledge there are only data on the role of the $\mathrm{Hh}$ pathway in normal salivary glands [42-44] and merely a few studies focusing on STAT3 [45-47] and minichromosome maintenance protein 3 (MCM3) in salivary gland neoplasms [48], the present study proposes to study the Hh pathway components and STAT3 in salivary gland neoplasms in an attempt to add to the knowledge of the biological

Table 2 Immunolabeling of Hh pathway components, STAT3, and MCM3 relative to morphological aspects of the different tumors studied and in the normal salivary gland

\begin{tabular}{|c|c|c|c|c|c|c|c|}
\hline Tumor & Cell type/stromal region & SHH & GLI1 & SUFU & HHIP & STAT3 & MCM3 \\
\hline \multirow{2}{*}{$\begin{array}{l}\text { Normal salivary gland } \\
\text { adjacent to } \\
\text { the tumor region }\end{array}$} & Ductal cells &,$+ \mathrm{a}$ &,$+ \mathrm{b}$ &,$+ \mathrm{a}$ &,$+ \mathrm{a}$ &,$+ \mathrm{a}$ & - \\
\hline & Acinar cells & - &,$+ \mathrm{a}$ & - & - & - & - \\
\hline \multirow[t]{6}{*}{ Pleomorphic adenoma } & Lumen cells &,$+ \mathrm{a}$ &,$+ \mathrm{b}$ &,$+ \mathrm{a}$ &,$+ \mathrm{a}$ &,$+ \mathrm{a}$ &,$+ \mathrm{b}$ \\
\hline & Ductal external cells & - &,$+ \mathrm{a}$ & - & - & - & - \\
\hline & Myoepithelial cells &,$+ \mathrm{a}$ &,$+ \mathrm{b}$ &,$+ \mathrm{a}$ &,$+ \mathrm{a}$ &,$+ \mathrm{a}$ &,$+ \mathrm{b}$ \\
\hline & Squamous metaplasia &,$+ \mathrm{a}$ &,$+ \mathrm{b}$ &,$+ \mathrm{a}$ &,$+ \mathrm{a}$ & - & - \\
\hline & Condroid stroma &,$+ \mathrm{a}$ & - &,$+ \mathrm{a}$ &,$+ \mathrm{a}$ & - & - \\
\hline & Stromal cells & - & - &,$+ \mathrm{a}$ &,$+ \mathrm{a}$ & - & - \\
\hline \multirow[t]{4}{*}{ Adenoid cystic carcinoma } & Lumen cells - tubular pattern &,$+ \mathrm{a}$ &,$+ \mathrm{b}$ &,$+ \mathrm{a}$ &,$+ \mathrm{a}$ &,$+ \mathrm{b}$ &,$+ \mathrm{b}$ \\
\hline & Cribriform pattern cells &,$+ \mathrm{a}$ &,$+ \mathrm{b}$ &,$+ \mathrm{a}$ &,$+ \mathrm{a}$ &,$+ \mathrm{b}$ &,$+ \mathrm{b}$ \\
\hline & Solid pattern cells &,$+ \mathrm{a}$ &,$+ \mathrm{b}$ &,$+ \mathrm{a}$ &,$+ \mathrm{a}$ &,$+ \mathrm{b}$ &,$+ \mathrm{b}$ \\
\hline & Stromal cells &,$+ \mathrm{a}$ & - &,$+ \mathrm{a}$ &,$+ \mathrm{a}$ & - & - \\
\hline \multirow[t]{6}{*}{ Mucoepidermoid carcinoma } & Epidermoid cells &,$+ \mathrm{a}$ &,$+ \mathrm{b}$ &,$+ \mathrm{a}$ &,$+ \mathrm{a}$ &,$+ \mathrm{a}$ &,$+ \mathrm{b}$ \\
\hline & Clear cells &,$+ \mathrm{a}$ &,$+ \mathrm{b}$ &,$+ \mathrm{a}$ &,$+ \mathrm{a}$ &,$+ \mathrm{a}$ &,$+ \mathrm{b}$ \\
\hline & Basal cells (cystic area) &,$+ \mathrm{a}$ &,$+ \mathrm{b}$ &,$+ \mathrm{a}$ &,$+ \mathrm{a}$ &,$+ \mathrm{a}$ &,$+ \mathrm{b}$ \\
\hline & Parabasal cells (cystic area) &,$+ \mathrm{a}$ &,$+ \mathrm{b}$ &,$+ \mathrm{a}$ &,$+ \mathrm{a}$ &,$+ \mathrm{a}$ &,$+ \mathrm{b}$ \\
\hline & Mucous and caliciform cells & - &,$+ \mathrm{b}$ & - & - &,$+ \mathrm{a}$ & - \\
\hline & Stromal cells &,$+ \mathrm{a}$ &,$+ \mathrm{b}$ &,$+ \mathrm{a}$ &,$+ \mathrm{a}$ & - & - \\
\hline
\end{tabular}

$(+)$ positive, $(-)$ negative, (a) cytoplasm, (b) nuclear 

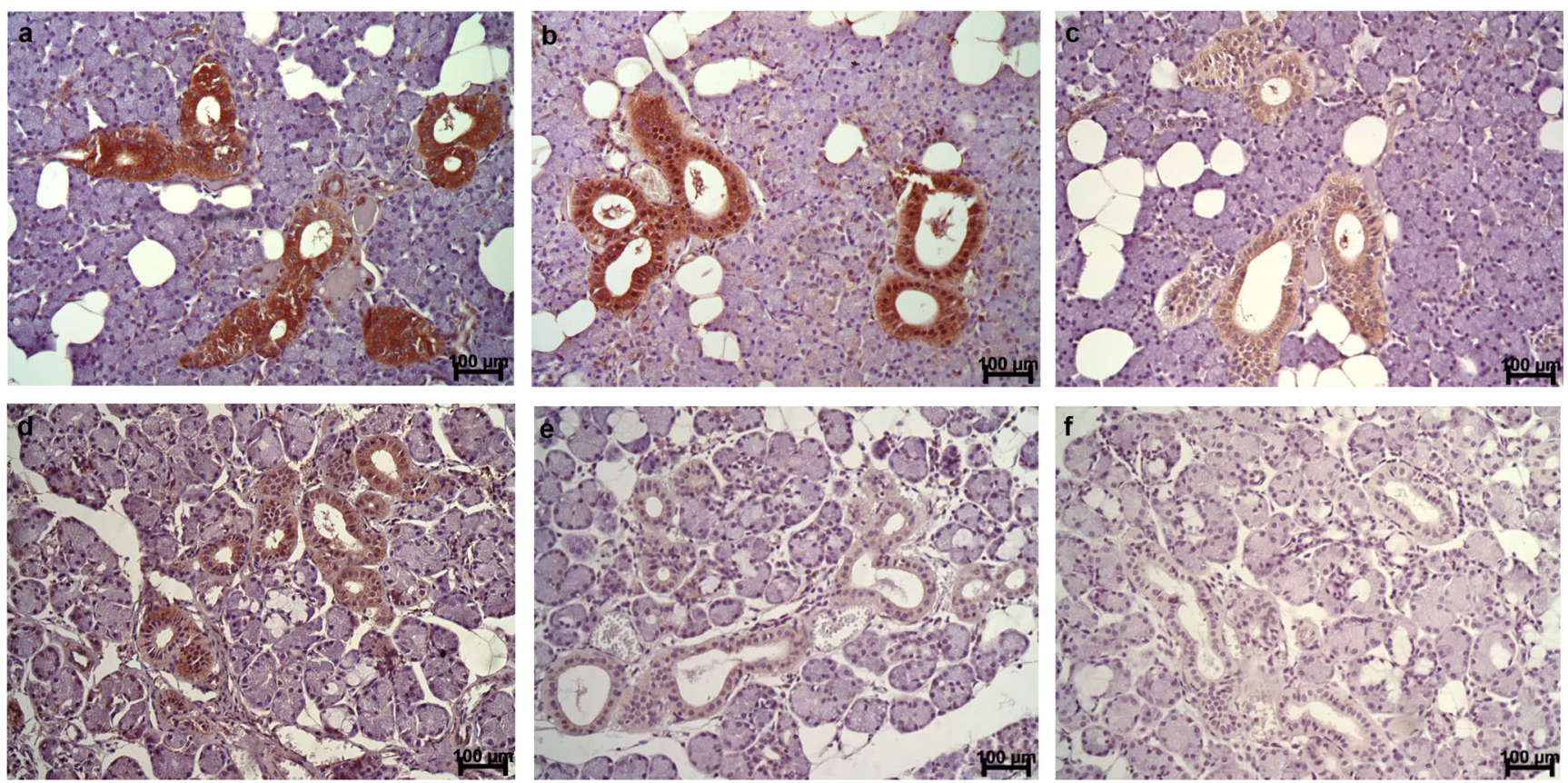

Fig. 1 Normal salivary gland: SHH immunolabeling: a cytoplasmic labeling of gland ductal cells; note the absence of labeling in the serous acini. GLI1 immunolabeling: b nuclear and cytoplasmic labeling of gland ductal cells; note predominant absence of labeling in the serous acini. SUFU immunolabeling: c cytoplasmic labeling of gland ductal cells;

characteristics of these neoplasms. As a new cellular proliferation marker known to play an important role in cell cycle progression [49-51], MCM3 was also included.

\section{Materials and methods}

Upon approval by the Research Ethics Committee (CAAE [Certificate of Submission for Ethical Evaluation]: 33413414.0.0000.5024, Opinion: 784.874), 9 PA cases, 20 MEC cases, and 17 ACC cases were obtained from the archives of Oral Surgical Pathology, School of Dentistry of the Federal University of Bahia (Faculdade de Odontologia da Universidade Federal da Bahia-FOUFBA) and AC Camargo Hospital (São Paulo (SP)) and were analyzed. Clinical data regarding age, gender, anatomical localization, and lesion size were obtained from the records of anatomopathological reports. In addition, salivary gland tissue, adjacent to the tumors, was also analyzed.

For the immunohistochemistry technique, 3- $\mu$ m-thick sections were prepared from formol-preserved, paraffinembedded material, and the sections were placed onto previously silanized glass slides. The EnVision Advance HRP (B) (Dako Corporation, Carpinteria, USA) system was used, following the protocol in Table 1. After antigen retrieval, endogenous peroxidase was blocked by immersion of tissue sections in a solution of $3 \%$ hydrogen peroxide and distilled water for $10 \mathrm{~min}$, protected from light. The note the absence of labeling in the serous acini. HHIP immunolabeling: d cytoplasmic labeling of gland ductal cells; note the absence of labeling in the serous acini. STAT3 immunolabeling: e discrete cytoplasmic labeling of gland ductal cells; note the absence of labeling in the serous acini. MCM3 immunolabeling: $\mathbf{f}$ absence of labeling

antibodies were diluted with background-reducing solution (Dako Corporation, Carpinteria, USA) and applied on the sections, and the sections were incubated for $18 \mathrm{~h}$ (overnight) at $4{ }^{\circ} \mathrm{C}$.

Two previously calibrated observers performed the analysis of the positively labeled cells using high-definition light microscopy (AXIOSTARPLUS, ZEISS, Germany 2008). For immunohistochemical evaluation of SHH, HHIP, GLI1, and SUFU and STAT3 antibodies, the cases were scored according to labeling intensity and proportion. Intensity was scored as follows: score $0=$ no staining, score $1=$ discrete staining, score $2=$ moderate staining, and score $3=$ intense staining. Labeling proportion was defined as the percentage of labeled cells $(0=0-10 \%, 1=11-25 \%, 2=26-$ $50 \%, 3=51-75 \%, 4=76-100 \%)$. The labeling index (LI) was calculated by multiplying the intensity $(0-3)$ by the proportion (from 0 to 4 ) as follows: $\mathrm{LI}=$ labeling intensity $\times$ labeled cells ratio. Next, we scored protein expression according to the LI: negative $(-)$ for $\mathrm{LI}=0$, low expression $(1+)$ for LI between 1 and 4 , high expression $(2+)$ for $\mathrm{LI} \geq 5$ [52-55].

For MCM3, positively labeled and unlabeled cells were counted manually, with $\times 400$ magnification, in 10 fields, and the images were transferred to a video monitor using a computerized system. Upon capture with a digital camera (AXIOCAM ICc3, ZEISS, Germany, 2008), the cases were analyzed using IMAGEJ $1.48 \mathrm{v}$ software (NIH Image, USA, 2014). Next, the percentage of labeled cells relative to the total 
Fig. 2 Pleomorphic adenoma: SHH immunolabeling: a strong labeling in myoepithelial cells and b in lumen cells of ductal structures. GLII immunolabeling: c layer of myoepithelial cells showing predominantly cytoplasmic labeling and $\mathbf{d}$ ductal cells with predominantly nuclear labeling. SUFU immunolabeling: e cytoplasmic labeling in lumen cells of ductal structures and $\mathbf{f}$ in myoepithelial cells. HHIP immunolabeling: g cytoplasmic labeling of lumen cells in a tubular-trabecular pattern; note the myxoid matrix with immunopositive cells and $\mathbf{h}$ cytoplasmic labeling of myoepithelial cells. STAT3 immunolabeling: $\mathbf{i}$ cytoplasmic labeling in lumen cells of ductal structures and myoepithelial cells. MCM3 immunolabeling: $\mathbf{j}$ focal accumulation of nuclear labeling in myoepithelial cells
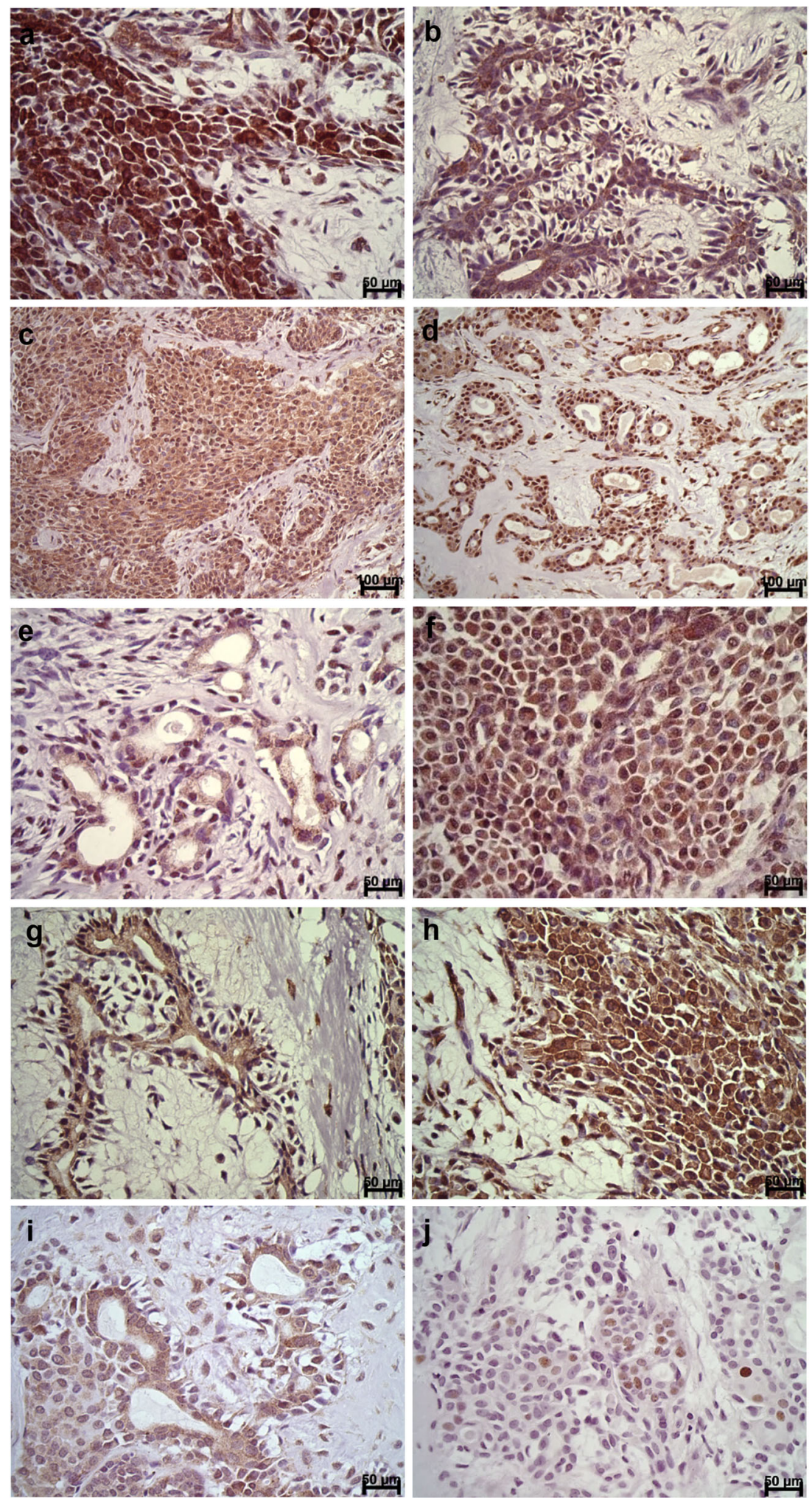

number of cells per field was calculated. To allow comparison with the remaining antibodies, the percentage obtained by MCM3 counts was classified according to scores, as previously described $(0=0-10 \%, 1=11-25 \%, 2=26-50 \%, 3=51-$
$75 \%, 4=76-100 \%$ ), and was multiplied by the labeling intensity.

Stromal labeling analysis was performed for all proteins using the LI, as previously described. 
Fig. 3 Adenoid cystic

carcinoma: $\mathrm{SHH}$

immunolabeling: a cytoplasmic

labeling in a tubular pattern and $\mathbf{b}$

in lumen cells of tubular

structures. GLI1 immunolabeling:

c nuclear labeling in cribriform

region of $\mathrm{ACC}$ and $\mathbf{d}$ in a more

solid region. SUFU

immunolabeling: e cribriform

pattern with small

immunopositive lumens and $\mathbf{f}$

cytoplasmic labeling in lumen

cells of ductal structures. HHIP

immunolabeling: $\mathbf{g}$ cytoplasmic

labeling of cribriform regions and

h tubular patterns with

immunolabeled cells. STAT3

immunolabeling: i nuclear

labeling in a cribriform pattern.

MCM3 immunolabeling: $\mathbf{j}$ nuclear

labeling in a solid region
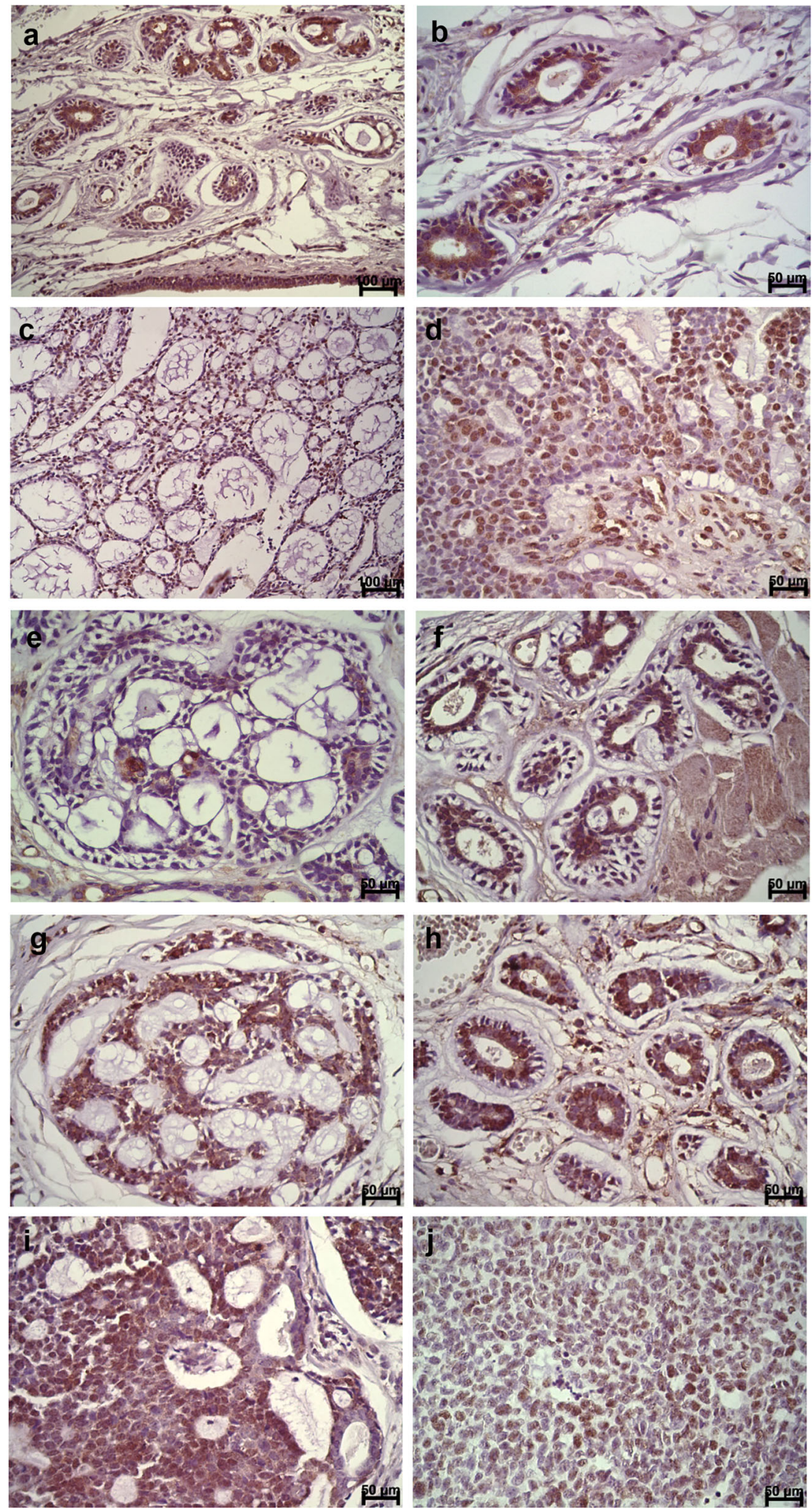

Moreover, labeling was scored according to its location: membrane and/or cytoplasm for SHH, HHIP, and SUFU; nucleus and/or cytoplasm for STAT3 and GLI1; and nucleus for MCM3. Positively labeled cellular types were also described.
A chi-square test was applied for the statistical analysis of antibody immunolabeling (SHH, HHIP, SUFU, GLI1, STAT3, and MCM3) for the different tumor types (PA, $\mathrm{ACC}$, and MEC). Then, to compare immunolabeling 
Fig. 4 Mucoepidermoid carcinoma: $\mathrm{SHH}$

immunolabeling: a cytoplasmic labeling of squamous cells in the cystic space. b Strong

cytoplasmic labeling of intermediate cells. GLII immunolabeling: c nuclear labeling in squamous cells in the cystic space and $\mathbf{d}$ nuclear labeling in a solid region of MEC. SUFU immunolabeling: e cytoplasmic labeling of squamous cells in the cystic space and $\mathbf{f}$ epidermoid cells. HHIP immunolabeling: $\mathbf{g}$ discrete cytoplasmic labeling of clear cells and $\mathbf{h}$ epidermoid cells. Note fibrous matrix with immunolabeled cells in (g) and (h). STAT3 immunolabeling: i solid region with predominance of immunolabeled epidermoid cells. MCM3 immunolabeling: $\mathbf{j}$ nuclear labeling in a solid region
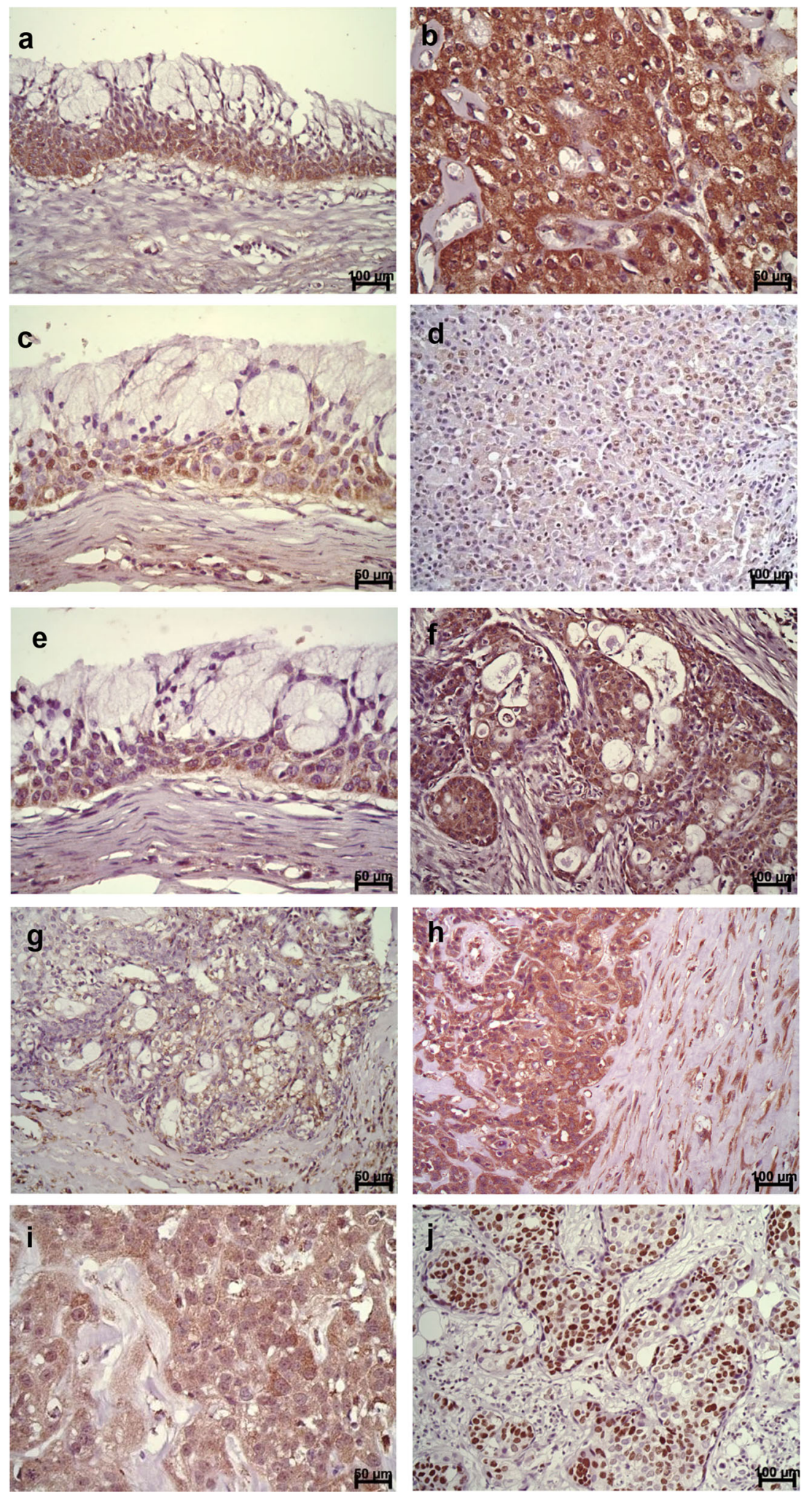

between two tumor groups, the LIs were categorized into two groups, high immunoexpression $(2+$ and $3+)$ and low immunoexpression $(-1$ and $1+)$, and an exact Fisher test was applied. Spearman correlation coefficients were determined for the correlations between the components of the Hh pathway, STAT3, and MCM3. All of the statistical calculations were performed using GraphPad Prism 6.03 software (GraphPad Software, San Diego, CA, 
Table 3 Comparisons between the expression of Hh pathway components, STAT3, and MCM3 among salivary gland tumors

\begin{tabular}{lllll}
\hline & PA & ACC & MEC & $p$ value \\
\hline SHH & & & & \\
Low expression & 1 & 9 & 2 & $0.0064^{*}$ \\
High expression & 8 & 8 & 18 & \\
GLI & & & & \\
Low expression & 5 & 3 & 5 & $0.0525^{* *}$ \\
High expression & 4 & 14 & 15 & \\
SUFU & & & & \\
Low expression & 1 & 7 & 1 & 0.1106 \\
High expression & 8 & 7 & 10 & \\
HHIP & & & & 0.1218 \\
Low expression & 5 & 5 & 6 & \\
High expression & 4 & 12 & 14 & $0.0003^{*}$ \\
STAT3 & & & & \\
Low expression & 9 & 8 & 18 & \\
High expression & 0 & 9 & 2 & \\
MCM3 & & & & \\
Low expression & 9 & 9 & 18 & \\
High expression & 0 & 8 & 2 & \\
\hline
\end{tabular}

*Statistically significant $(p<0.05) ; * *$ Trend

USA). The results were considered statistically significant when $p<0.05$.

\section{Results}

Table 2 and Figs. 1, 2, 3, and 4 show the immunolabeling of components of the Hh pathway, STAT3, and MCM3 relative to the morphological aspects of the different tumors studied and in the normal salivary gland.

Table 3 shows the comparison of expression of components of the Hh pathway, STAT3, and MCM3 between salivary gland tumors. There was significantly high SHH expression when PA $(p<0.05$, chi-square test) and MEC ( $p<0.05$, chi-square test) were compared, whereas STAT3 showed a significantly low expression when PA and MEC were compared $(p<0.05$, chi-square test). However, when we compared the expressions of all of these components and the cribriform and solid ACC, we did not observe significant differences relative to high and low expression $(p>0.05$, exact Fisher test, Table 4) nor when the different MEC malignancy grades were compared ( $p>0.05$, exact Fisher test, Table 5). Table 6 shows a summary of $\mathrm{Hh}$ pathway results and clinical parameters of PA.

Table 7 shows the relationships between the components of the Hh pathway, STAT3, and MCM3 in PA, ACC, and MEC, but we did not observe significant correlations $(p>0.05$, Spearman correlation coefficients).
Table 8 and Fig. 5 show the results of the expression of the components of the Hh pathway, STAT3, and MCM3 in the parenchyma and stroma of the different salivary gland tumors (exact Fisher test).

When we compared the relationships between immunoexpression of the components of the Hh pathway, STAT3, and MCM3 and clinical parameters such as gender, age $(<40$ and $\geq 40)$, localization, size $(<3 \mathrm{~cm}, \geq 3 \mathrm{~cm})$ and perineural invasion in ACC and MEC, we did not observe significant relationships $(p>0.05$, exact Fisher test) (Tables 4 and 5).

\section{Discussion}

Our results showed high expression of Hh signaling pathway components for the majority of salivary gland tumors studied, suggesting that the Hh signaling pathway participates in the development of these tumors. In contrast, low expression was observed for MCM3 for the majority of cases under study, whereas STAT3 seemed to be active only in ACC cases, especially due to its nuclear expression. However, to our knowledge, this study is the first to highlight the role of the $\mathrm{Hh}$ pathway in salivary gland tumors.

PA tumors showed A significantly high expression of $\mathrm{SHH}$ ligand compared to ACC. These results were similar to those obtained by Xu et al. [56], who also observed high expression of Hh signaling components in benign thyroid tumors. Other studies also observed high expression of Hh pathway components in benign tumors, such as gastric adenomas [57], intestinal adenomas [58], and ameloblastomas [59]. These findings suggest that the Hh pathway may be active in the early stages of tumor development, thus participating in the development of benign neoplasms of the salivary gland, such as PA.

Likewise, in the present study, the majority of MEC cases presented a significantly high expression of SHH ligand, especially in relation to ACC. GLI1 showed a predominance of nuclear expression. Some authors claim that GLI1 is the main indicator of Hh pathway activation $[16,53,60]$. Studies have reported the high expression of nuclear GLI1 in malignant thyroid neoplasms [56] and in oral squamous cell carcinoma [26]. Therefore, it is possible to suggest that the Hh pathway is active in MEC and that it also participates in the development of this tumor.

Although a little more than $50 \%$ of the ACC cases present low SHH expression, the majority presented high nuclear GLI1 expression, which suggests that the Hh pathway is active in ACC, but possibly in a manner independent of $\mathrm{SHH}$ ligand. However, the Hh pathway may become active regardless of the ligand, which occurs through activation mechanisms downstream of SMO and is known as either the alternative pathway or the SMO-independent pathway [61]. Some potential causes for this ligand-independent activation are 


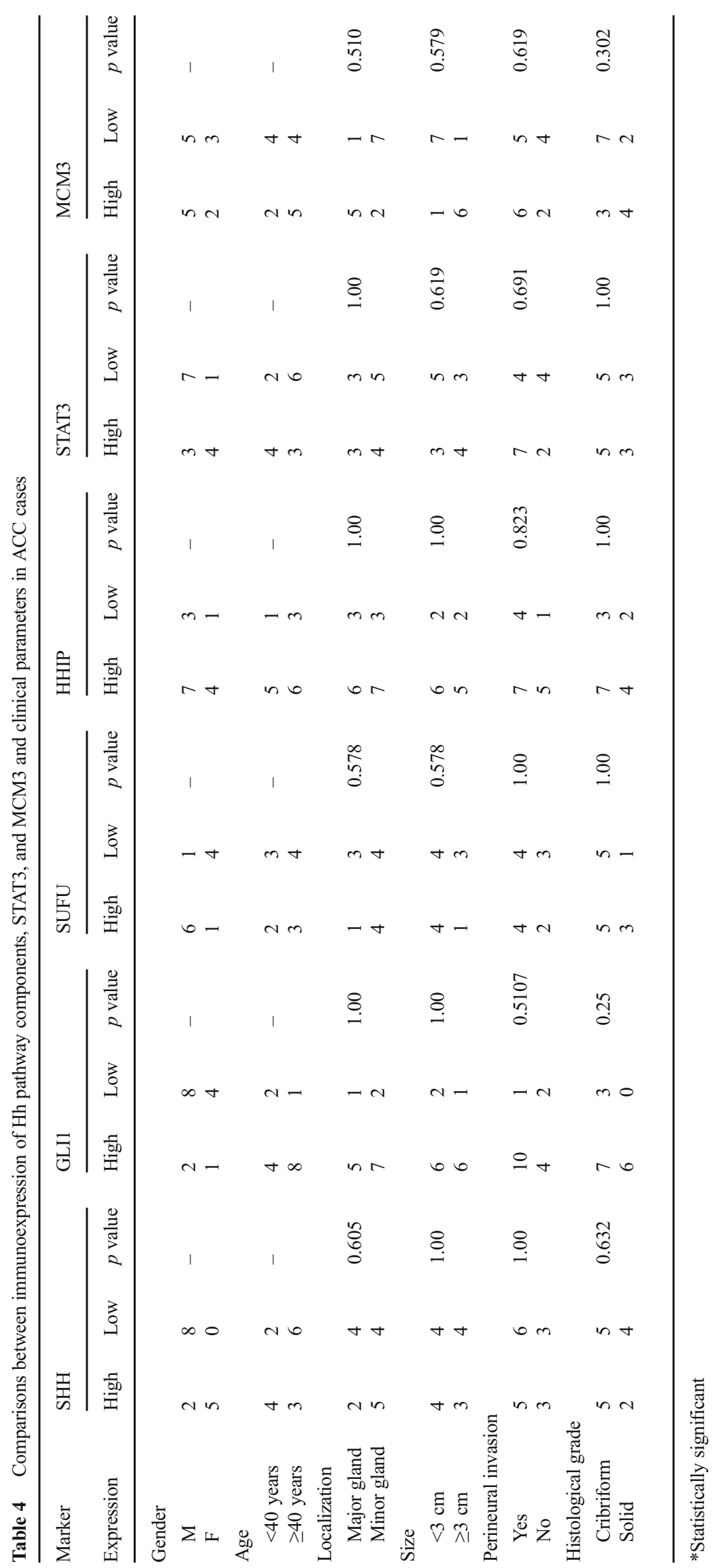




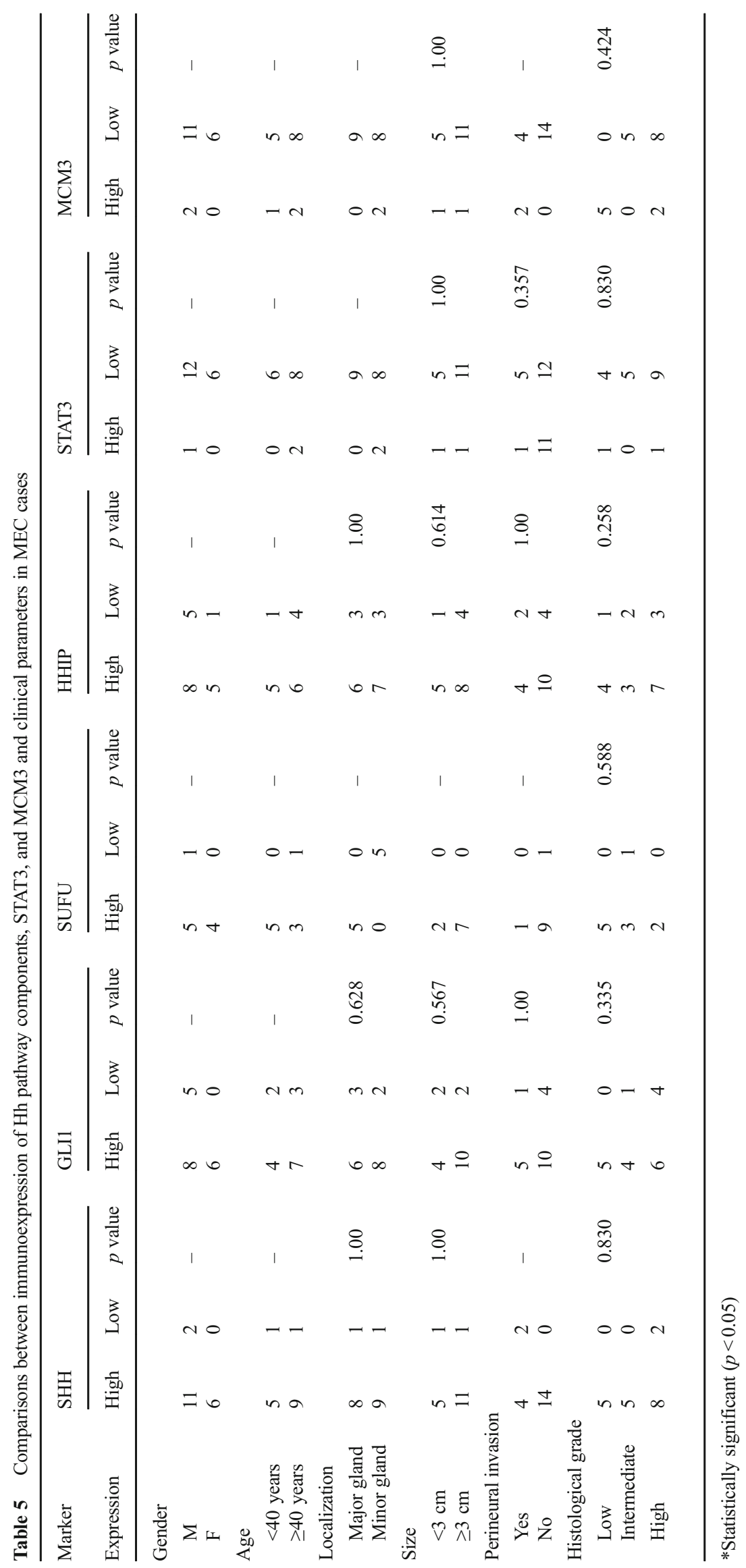


Table 6 Scores of Hh pathway components, STAT3, and MCM3 in relation to the clinical parameters in PA cases ${ }^{\S}$

\begin{tabular}{|c|c|c|c|c|c|c|c|c|c|c|c|c|}
\hline \multirow{2}{*}{$\begin{array}{l}\text { Marker } \\
\text { Expression }\end{array}$} & \multicolumn{2}{|l|}{ SHH } & \multicolumn{2}{|l|}{ GLI1 } & \multicolumn{2}{|c|}{ SUFU } & \multicolumn{2}{|l|}{ HHIP } & \multicolumn{2}{|c|}{ STAT3 } & \multicolumn{2}{|c|}{ MCM3 } \\
\hline & High & Low & High & Low & High & Low & High & Low & High & Low & High & Low \\
\hline \multicolumn{13}{|l|}{ Gender } \\
\hline M & 4 & 1 & 3 & 2 & 4 & 1 & 1 & 4 & 0 & 5 & 0 & 5 \\
\hline $\mathrm{F}$ & 3 & 0 & 1 & 2 & 3 & 0 & 2 & 1 & 0 & 3 & 0 & 3 \\
\hline \multicolumn{13}{|l|}{ Age } \\
\hline$<40$ years & 6 & 0 & 4 & 2 & 6 & 0 & 2 & 4 & 0 & 6 & 0 & 6 \\
\hline$\geq 40$ years & 1 & 1 & 1 & 1 & 1 & 1 & 1 & 1 & 0 & 2 & 0 & 2 \\
\hline \multicolumn{13}{|l|}{ Localization } \\
\hline Major gland & 3 & 0 & 1 & 2 & 3 & 0 & 2 & 1 & 0 & 3 & 0 & 3 \\
\hline Minor gland & 5 & 1 & 4 & 2 & 5 & 1 & 2 & 4 & 0 & 6 & 0 & 6 \\
\hline \multicolumn{13}{|l|}{ Size } \\
\hline$<3 \mathrm{~cm}$ & 3 & 1 & 3 & 1 & 3 & 1 & 3 & 1 & 0 & 4 & 0 & 4 \\
\hline$\geq 3 \mathrm{~cm}$ & 2 & 0 & 0 & 2 & 1 & 1 & 1 & 1 & 0 & 2 & 0 & 2 \\
\hline
\end{tabular}

$\S$ It was not possible to perform statistical tests because of the sample size

genetic mutations, ciliary protein expression, and interactions with other independent signaling pathways [61].

A study conducted by Olsen et al. [62] detected a decrease in HHIP expression in liver, stomach, colon, rectal, and lung cancer specimens when compared to normal counterparts, suggesting a tumor suppressor role for HHIP. In contrast, the HHIP protein is positively regulated in response to Hh pathway activation, as HHIP is a target gene of the pathway [17,

Table 7 Correlations between Hh pathway components, STAT3, and MCM3

\begin{tabular}{lll}
\hline & Spearman $r$ & $p$ value \\
\hline SHH/STAT3 & & \\
PA & -0.5443 & 0.4167 \\
ACC & -0.5000 & 0.4167 \\
MEC & -0.3333 & 0.7500 \\
GLI1/STAT3 & & \\
PA & 0.9428 & 0.0833 \\
ACC & -0.3162 & 0.7500 \\
MEC & -0.3134 & 0.7500 \\
SHH/GLI1 & & \\
PA & -0.05556 & 0.9167 \\
ACC & 0.2128 & 0.9167 \\
MEC & 0.9487 & 0.0833 \\
MCM3/GLI1 & & \\
PA & 0.5000 & 0.4167 \\
ACC & -0.4000 & 0.7500 \\
MEC & -0.9487 & 0.0833 \\
\hline
\end{tabular}

*Statistically significant $(p<0.05)$
18]. In the present study, the majority of the ACC and MEC cases showed high HHIP expression, whereas the PA cases showed low expression. Although this difference was not significant, the data suggest that the high nuclear expression of GLI1, present in ACC and MEC, triggered HHIP overexpression in the ACC and MEC cases.

Some studies have demonstrated the role of SUFU in tumor suppression [53, 63]; however, one study detected overexpression of the tumor suppressor protein SUFU in prostate cancer [28]. In the present study, high SUFU expression was also observed in most MEC and PA cases and in half of the ACC cases. This finding may be due to the positive role of SUFU on the Hh pathway [64]. Liu et al. [64] believe that in the presence of SUFU, inactive GLI is protected from degradation, as it is associated with SUFU and can be subsequently activated. In this way, SUFU enables maximal and continual activation of the Hh pathway. In contrast, GLI proteins are degraded rapidly in the absence of SUFU, which could prevent maximal activation of the pathway.

We observed significant high parenchymal labeling of components of the Hh pathway in ACC and MEC cases compared to stromal labeling. Moreover, fibroblast and blood vessel labeling was observed in some PA and MEC cases. A study conducted by Leovic et al. [65] in oral and oropharyngeal squamous cell carcinoma showed parenchymal labeling for SHH, PTCH1, and GLI1 and also detected stromal labeling for these proteins. Some reports claim that the SHH ligand produced by tumor epithelial cells may activate the Hh pathway in mesenchymal cells, rendering the stroma favorable for tumor development $[66,67]$. In this respect, it is possible that Hh components play a role in the epithelial mesenchymal transition in salivary gland tumors. 
Table 8 Comparison of expression levels of Hh pathway components in the parenchyma and stroma of different salivary gland tumors

\begin{tabular}{|c|c|c|c|c|c|c|c|c|c|c|}
\hline \multirow[t]{2}{*}{ Marker } & \multirow[t]{2}{*}{ Immunoexpression } & \multicolumn{3}{|l|}{ PA } & \multicolumn{3}{|l|}{$\mathrm{ACC}$} & \multicolumn{3}{|l|}{ MEC } \\
\hline & & Parenchyma & Stroma & $p$ value & Parenchyma & Stroma & $p$ value & Parenchyma & Stroma & $p$ value \\
\hline SHH & $\begin{array}{l}\text { High } \\
\text { Low }\end{array}$ & $\begin{array}{l}8 \\
1\end{array}$ & $\begin{array}{l}5 \\
4\end{array}$ & 0.2941 & $\begin{array}{l}8 \\
9\end{array}$ & $\begin{array}{l}1 \\
16\end{array}$ & 0.0167 & $\begin{array}{l}18 \\
2\end{array}$ & $\begin{array}{l}5 \\
15\end{array}$ & $<0.0001^{*}$ \\
\hline GLI1 & $\begin{array}{l}\text { High } \\
\text { Low }\end{array}$ & $\begin{array}{l}4 \\
5\end{array}$ & $\begin{array}{l}1 \\
8\end{array}$ & 0.2941 & $\begin{array}{l}14 \\
3\end{array}$ & $\begin{array}{l}1 \\
16\end{array}$ & $<0.0001^{*}$ & $\begin{array}{l}15 \\
5\end{array}$ & $\begin{array}{l}7 \\
13\end{array}$ & $0.0002 *$ \\
\hline SUFU & $\begin{array}{l}\text { High } \\
\text { Low }\end{array}$ & $\begin{array}{l}8 \\
1\end{array}$ & $\begin{array}{l}4 \\
5\end{array}$ & 0.1312 & $\begin{array}{l}7 \\
7\end{array}$ & $\begin{array}{l}0 \\
14\end{array}$ & $0.0058^{*}$ & $\begin{array}{l}10 \\
1\end{array}$ & $\begin{array}{l}4 \\
7\end{array}$ & $0.0237^{*}$ \\
\hline HHIP & $\begin{array}{l}\text { High } \\
\text { Low }\end{array}$ & $\begin{array}{l}4 \\
5\end{array}$ & $\begin{array}{l}2 \\
7\end{array}$ & 0.6199 & $\begin{array}{l}12 \\
5\end{array}$ & $\begin{array}{l}3 \\
14\end{array}$ & $0.0049 *$ & $\begin{array}{l}14 \\
6\end{array}$ & $\begin{array}{l}5 \\
15\end{array}$ & $0.0104 *$ \\
\hline
\end{tabular}

*Statistically significant $(p<0.05)$

Some studies have demonstrated the role of the Hh pathway in the morphogenesis of the salivary glands [42-44] and, as shown here, the Hh pathway components also seem to exert important actions in PA, ACC, and MEC morphogenesis, considering their presence in the different morphological patterns of these neoplasms. In this regard, through in vivo studies using salivary gland cell culture, Jaskoll et al. [42] concluded that the Hh pathway participates in epithelial proliferation and submandibular gland morphogenesis. Another study demonstrated that this pathway promotes lumen formation and epithelial polarization during salivary gland development in mice [43], whereas another study reported hyperplasic and metaplastic alterations and acinar differentiation blockade [44]. In the present study, SHH, HHIP, SUFU, and GLI1 labeling was observed in regions of morphologically normal salivary gland tissue, adjacent to the ACC and MEC cases, mainly in the ductal cells. Considering that ACC and MEC originate from intercalary and secretory ductal cells, respectively [6], and that ductal cells present the capacity for proliferation, although low [68], we suggest that the components of the Hh pathway may participate in the tumorigenesis of neoplasms of the salivary gland.

In the PA and ACC cases studied, labeling of Hh pathway components was mainly observed in lumen cells, whereas the more external ductal cells were not labeled. These findings are similar to what was observed for the components of the $\mathrm{Hh}$ pathway in the normal salivary gland, allowing us to suggest a state of preservation of lumen cell differentiation.

Previous studies have demonstrated the oncogenic potential of STAT3, as this protein is constitutively in salivary gland cancer [45-47]. In the present study, cytoplasmic STAT3 labeling was observed in the duct cells of morphologically normal salivary glands and exhibited high nuclear expression in ACC, whereas PA and MEC presented cytoplasmic labeling; the differences were statistically significant. These results were similar to those obtained by Araújo et al. [45]. Therefore, it is possible that STAT3 plays an important role in the regulation of processes associated with cell proliferation and survival in ACC, but not in PA and MEC.

We observed high GLI1 and STAT3 expression in ACC; however, there was no significant correlation between the two proteins, which suggests that they have an important function in ACC development, but in an independent manner. In contrast, some studies have shown correlations between STAT3 and Hh pathway components [22, 38, 54, 69]. Sengupta et al. [22] observed that the HH signaling pathway induces STAT3 phosphorylation and activation in chronic myeloid leukemia. Recently, a study conducted in papilliferous carcinoma of the thyroid showed positive and significant associations between pSTAT and Hh pathway components; however, the mechanism through which the Hh pathway induces STAT3 phosphorylation is still unclear [54].

MCM3 is a DNA-binding protein that plays an important role in cell cycle initiation and progression in eukaryotic cells $[48,50,70]$. In the present study, PA and MEC presented low MCM3 expression, while ACC showed high expression in only half of the cases; this difference was statistically significant. According to our results, MCM3 does not seem to be a good proliferation marker for salivary gland tumors, although there was a tendency for a correlation with MEC cases, taking this protein and GLI1 into account. Therefore, new studies must be performed to evaluate the effectiveness of MCM3 as a proliferation marker in salivary gland tumors.

Expression analysis of the proteins studied in the different ACC histological types (cribriform and solid) was performed; however, no statistically significant differences were observed. In the MEC histological grades, although not statistically significant, low-grade tumors showed lower LIs for SHH, GLI1, and MCM3 and higher indices for SUFU and HHIP. In high-grade tumors, higher LIs were observed for SHH, GLI1, HHIP, and MCM3. We suggest that the Hh pathway seems to have a greater participation in high-grade MEC development when compared to the remaining grades, as this 

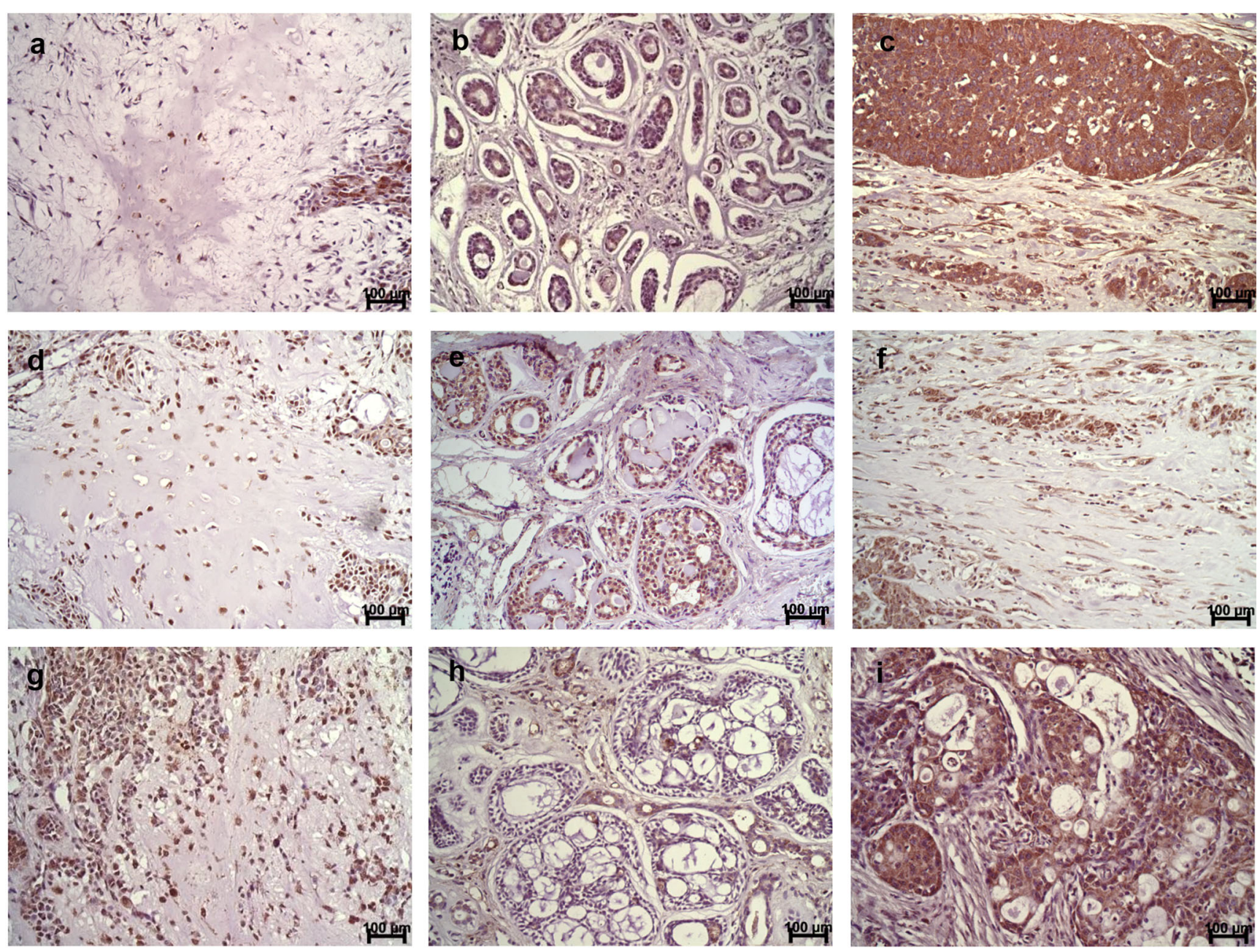
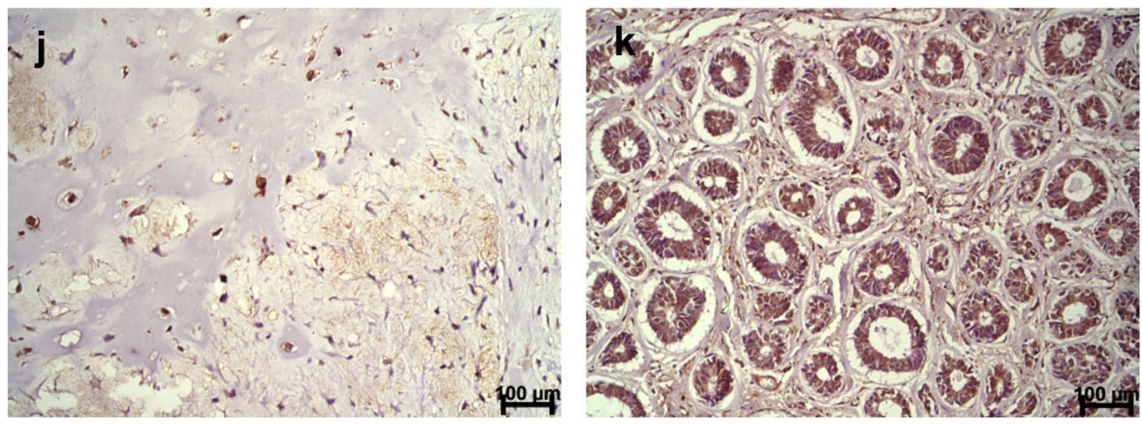

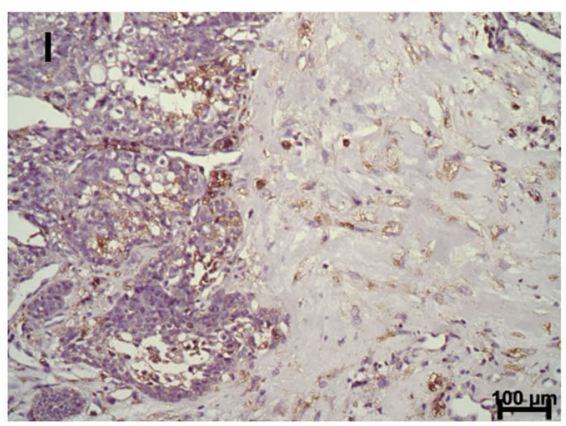

Fig. 5 Stroma immunolabeling. $S H H$ : a Pleomorphic adenoma: condroid matrix showing discrete cell labeling. b Adenoid cystic carcinoma: matrix with few cells, negative for SHH. c Mucoepidermoid carcinoma: fibrous matrix with immunolabeled cells. GLI1: d Pleomorphic adenoma: condroid matrix with immunolabeled cells. e Adenoid cystic carcinoma: fibrous matrix negative for GLI1. f Mucoepidermoid carcinoma: fibrous matrix with immunolabeled cells. SUFU: g Pleomorphic adenoma: myxoid matrix with disperse

histological type presents a worse prognosis. Our findings corroborate the study by Li et al. [71], in which higher SHH, PTCH, and GLI1 expression levels were detected in high malignancy grade gliomas than in low malignancy grade gliomas. immunolabeled cells. h Adenoid cystic carcinoma: matrix with few cells, with discrete SUFU labeling. i Mucoepidermoid carcinoma: fibrous matrix with discrete SUFU labeling. HHIP: j Pleomorphic adenoma: condroid and myxoid matrix with immunolabeled cells. $\mathbf{k}$ Adenoid cystic carcinoma: fibrous matrix with immunolabeled cells. $\mathbf{l}$ Mucoepidermoid carcinoma: fibrous matrix with discrete immunolabeling

When comparing clinical data such as gender, age, localization, size, and perineural invasion with the Hh pathway components, STAT3, and MCM3, no significant differences were observed. Studies conducted in oral squamous cell carcinoma showed that activation of the Hh pathway is 
associated with recurrence and lymph node metastases [26, 72]. For STAT3, a study conducted in squamous cell carcinoma of the esophagus showed that high STAT3 expression is associated with tumors at advanced stages; however, no associations were observed with age, gender, invasion, and histological grade [73]. Thus, we suggest that new studies should be conducted in salivary gland tumors to establish a relationship between Hh, STAT3, and MCM3 and other clinical characteristics associated with patient survival.

Finally, the results of our study suggest a potential participation of the $\mathrm{Hh}$ in the development and maintenance of the cytoarchitectural pattern of PA, ACC, and MEC, along with the participation of STAT3 in ACC development, irrespective of perineural infiltration. In addition, MCM3 does not seem to be a good proliferation marker for salivary gland tumors. We suggest that new studies be conducted and aimed at understanding the mechanism by which the Hh pathway and STAT3 promote the growth and progression of these tumors and identifying inhibitors of these pathways so that it will become possible to apply new therapies in the treatment of salivary gland tumors.

\section{References}

1. Yih WY, Kratochvil FJ, Stewart JC. Intraoral minor salivary gland neoplasms: review of 213 cases. J Oral Maxillofac Surg. 2005;63: 805-10.

2. Li LJ, Li Y, Wen YM, Liu H, Zhao HW. Clinical analysis of salivary gland tumor cases in west China in past 50 years. Oral Oncol. 2008;44:187-92.

3. Stenman G, Persson F, Andersson MK. Diagnostic and therapeutic implications of new molecular biomarkers in salivary gland cancers. Oral Oncol. 2014;50:683-90.

4. Al-Khateeb TH, Ababneh KT. Salivary tumors in north Jordanians: a descriptive study. Oral Surg Oral Med Oral Pathol Oral Radiol Endod. 2007;103:53-9.

5. Nagao T, Sato E, Inoue R, Oshiro H, Takahashi R, Nagai T, et al. Immunohistochemical analysis of salivary gland tumors: application for surgical pathology practice. Acta Histochem Cytochem. 2012;45:269-82.

6. Adams A, Warner K, Nör JE. Salivary gland cancer stem cells. Oral Oncol. 2013;49:845-53

7. Amit M, Binenbaum Y, Trejo-Leider L, Sharma K, Ramer N, Ramer I, et al. International collaborative validation of intraneural invasion as a prognostic marker in adenoid cystic carcinoma of the head and neck. Head Neck. 2015;37:1038-45.

8. Toftgard R. Hedgehog signalling in cancer. Cell Mol Life Sci. 2000;57:1720-31.

9. Ruiz I, Altaba A, Sánchez P, Dahmane N. GLI and hedgehog in cancer: tumours, embryos and stem cells. Nat Rev Cancer. 2002;2: 361-72.

10. Cheng WT, Xu K, Tian DY, Zhang ZG, Liu LJ, Chen Y. Role of Hedgehog signaling pathway in proliferation and invasiveness of hepatocellular carcinoma cells. Int J Oncol. 2009;34:829-36.

11. Dai J, Ai K, Du Y, Chen G. Sonic hedgehog expression correlates with distant metastasis in pancreatic adenocarcinoma. Pancreas. 2011;40:233-6.
12. Amakye D, Jagani Z, Dorsch M. Unraveling the therapeutic potential of the Hedgehog pathway in cancer. Nat Med. 2013;19:1410 22.

13. Cohen MM. The hedgehog signaling network. Am J Med Genet A. 2003;123A:5-28.

14. Ma G, Xiao Y, He L. Recent progress in the study of Hedgehog signaling. J Genet Genomics. 2008;35:129-37.

15. Tzelepi V, Karlou M, Wen S, Hoang A, Logothetis C, Troncoso P, et al. Expression of hedgehog pathway components in prostate carcinoma microenvironment: shifting the balance towards autocrine signalling. Histopathology. 2011;58:1037-47.

16. Merchant JL. Hedgehog signalling in gut development, physiology and cancer. J Physiol. 2012;590:421-32.

17. Chuang PT, Mcmahon AP. Vertebrate hedgehog signalling modulated by induction of a hedgehog-binding protein. Nature. 1999;397:617-21.

18. Bosanac I, Maun HR, Scales SJ, Wen X, Lingel A, Bazan JF, et al. The structure of SHH in complex with HHIP reveals a recognition role for the shh pseudo active site in signaling. Nat Struct Mol Biol. 2009;16:691-7.

19. Merchant M, Vajdos FF, Ultsch M, Maun HR, Wendt U, Cannon J, et al. Suppressor of fused regulates GLI activity through a dual binding mechanism. Mol Cell Biol. 2004;24:8627-41.

20. Jia J, Kolterud A, Zeng H, Hoover A, Teglund S, Toftgärd R, et al. Suppressor of fused inhibits mammalian hedgehog signaling in the absence of cilia. Dev Biol. 2009;330:452-60.

21. Min TH, Kriebel M, Hou S, Pera EM. The dual regulator SUFU integrates hedgehog and wnt signals in the early xenopus embryo. Dev Biol. 2011;358:262-76.

22. Sengupta A, Banerjee D, Chandra S, Banerji SK, Ghosh R, Roy R, et al. Deregulation and cross talk among sonic hedgehog, wnt, hox and notch signaling in chronic myeloid leukemia progression. Leukemia. 2007;21:949-55.

23. Im S, Choi HJ, Yoo C, Jung JH, Jeon YW, Suh YJ, et al. Hedgehog related protein expression in breast cancer: GLI-2 is associated with poor overall survival. Korean J Pathol. 2013;47:116-23.

24. Wan J, Zhou J, Zhao H, Wang M, Wei Z, Gao H, et al. Sonic hedgehog pathway contributes to gastric cancer cell growth and proliferation. Biores Open Access. 2014;3:53-9.

25. Yang L, Wang LS, Chen XL, Gatalica Z, Qiu S, Liu Z, et al. Hedgehog signaling activation in the development of squamous cell carcinoma and adenocarcinoma of esophagus. Int J Biochem Mol Biol. 2012;3:46-57A.

26. Wang YF, Chang CJ, Lin CP, Chang SY, Chu PY, Tai SK, et al. Expression of hedgehog signaling molecules as a prognostic indicator of oral squamous cell carcinoma. Head Neck. 2012;34:155661.

27. Hao K, Tian XD, Qin CF, Xie XH, Yang YM. Hedgehog signaling pathway regulates human pancreatic cancer cell proliferation and metastasis. Oncol Rep. 2013;29:1124-32.

28. Kim TJ, Lee JY, Hwang TK, Kang CS, Choi YJ. Hedgehog signaling protein expression and its association with prognostic parameters in prostate cancer: a retrospective study from the view point of new 2010 anatomic stage/prognostic groups. J Surg Oncol. 2011;104:472-9.

29. Hinterseher U, Wunderlich A, Roth S, Ramaswamy A, Bartsch DK, Hauptmann S, et al. Expression of hedgehog signalling pathway in anaplastic thyroid cancer. Endocrine. 2014;45:439-47.

30. Darnell JE. Stats and gene regulation. Science. 1997;277:1630-5.

31. Dobi E, Monnien F, Kim S, Ivanaj A, N'guyen T, Demarchi M, et al. Impact of STAT3 phosphorylation on the clinical effectiveness of anti-EGFR-based therapy in patients with metastatic colorectal cancer. Clin Colorectal Cancer. 2013;12:28-36.

32. Han Z, Feng J, Hong Z, Chen L, Li W, Liao S, et al. Silencing of the STAT3 signaling pathway reverses the inherent and induced 
chemoresistance of human ovarian cancer cells. Biochem Biophys Res Commun. 2013;435:188-94.

33. Subramaniam A, Shanmugam MK, Perumal E, Li F, Nachiyappan A, Dai X, et al. Potential role of signal transducer and activator of transcription (STAT) 3 signaling pathway in inflammation, survival, proliferation and invasion of hepatocellular carcinoma. Biochim Biophys Acta. 2013;1835:46-60.

34. Chung SS, Giehl N, Wu Y, Vadgama JY. STAT3 activation in HER2-overexpressing breast cancer promotes epithelialmesenchymal transition and cancer stem cell traits. Int J Oncol. 2014;44:403-11.

35. Xu YH, Lu S. A meta-analysis of STAT3 and phospho-STAT3 expression and survival of patients with non-small-cell lung cancer. Eur J Surg Oncol. 2014;40:311-7.

36. Bromberg JF, Wrzeszczynska MH, Devgan G, Zhao Y, Pestell RG, Albanese C, et al. STAT3 as an oncogene. Cell. 1999;98:295-303.

37. Song L, Turkson J, Karras JG, Jove R, Haura EB. Activation of STAT3 by receptor tyrosine kinases and cytokines regulates survival in human non-small cell carcinoma cells. Oncogene. 2003;22: 4150-65.

38. Li Y, Du H, Qin Y, Roberts J, Cummings OW, Yan C. Activation of the signal transducers and activators of the transcription 3 pathway in alveolar epithelial cells induces inflammation and adenocarcinomas in mouse lung. Cancer Res. 2007;67:8494-503.

39. Yu H, Pardoll D, Jove R. STATS in cancer inflammation and immunity: a leading role for STAT3. Nat Rev Cancer. 2009;9:798809.

40. Gurgel CA, Buim ME, Carvalho KC, Sales CB, Reis MG, De Souza RO, et al. Transcriptional profiles of SHH pathway genes in keratocystic odontogenic tumor and ameloblastoma. J Oral Pathol Med. 2014;43:619-26.

41. Bournazou E, Bromberg J. Targeting the tumor microenvironment JAK-STAT3 signaling. Jakstat. 2013;2:1-8.

42. Jaskoll T, Leo T, Witcher D, Ormestad M, Astorga J, Bringas Jr P, et al. Sonic hedgehog signaling plays an essential role during embryonic salivary gland epithelial branching morphogenesis. Dev Dyn. 2004:229:722-32.

43. Hashizume A, Hieda Y. Hedgehog peptide promotes cell polarization and lumen formation in developing mouse submandibular gland. Biochem Biophys Res Commun. 2006;339:996-1000.

44. Fiaschi M, Kolterud A, Nilsson M, Toftgärd R, Rozell B. Targeted expression of GLI1 in the salivary glands results in an altered differentiation program and hyperplasia. Am J Pathol. 2011;179: 2569-79.

45. de Araújo VC, Furuse C, Cury PR, Altemani A, De Araújo NS. STAT3 expression in salivary gland tumours. Oral Oncol. 2008;44: 439-45.

46. Nikitakis NG, Scheper MA, Papanikolaou VS, Sklavounou A, Sauk JJ. Immunohistochemical expression of the oncogenic molecules active STAT3 and survivin in benign and malignant salivary gland tumors. Oral Surg Oral Med Oral Pathol Oral Radiol Endod. 2009; 107:837-43.

47. Ettl T, Stiegler C, Zeitler K, Agaimy A, Zenk J, Reichert TE, et al. EGFR, HER2, survivin, and loss of pSTAT3 characterize highgrade malignancy in salivary gland cancer with impact on prognosis. Hum Pathol. 2012;43:921-31.

48. Ashkavandi ZJ, Najvani AD, Tadbir AA, Pardis S, Ranjbar MA, Ashraf MJ. MCM3 as a novel diagnostic marker in benign and malignant salivary gland tumors. Asian Pac J Cancer Prev. 2013;14:3479-82.

49. Madine MA, Swietlik M, Pelizon C, Romanowski P, Mills AD, Laskey RA. The roles of the MCM, ORC, and CDC6 proteins in determining the replication competence of chromatin in quiescent cells. J Struct Biol. 2000;129:198-210.

50. Forsburg SL. Eukaryotic MCM, proteins: beyond replication initiation. Microbiol Mol Biol Rev. 2004;68:109-31.
51. Lameira AG, Pontes FS, Guimarães DM, Alves AC. D\# Jesus AS, Pontes HA, et al. MCM3 could be a better marker than KI-67 for evaluation of dysplastic oral lesions: an immunohistochemical study. J Oral Pathol Med. 2014;43:427-34.

52. Dultra FK, Barros AC, Schaer-Barbosa H, Figueiredo AL, Gurgel CA, Ramos EA, et al. Immunohistochemical assessment of CD1 apositive langerhans cells and their relationship with e-cadherin in minor salivary gland tumors. J Oral Pathol Med. 2012;41:47-53.

53. Yan R, Peng X, Yuan X, Huang D, Chen J, Lu Q, et al. Suppression of growth and migration by blocking the hedgehog signaling pathway in gastric cancer cells. Cell Oncol (Dordr). 2013;36:421-35.

54. Dong W, Cui J, Tian X, He L, Wang Z, Zhang P, et al. Aberrant sonic hedgehog signaling pathway and STAT3 activation in papillary thyroid cancer. Int J Clin Exp Med. 2014;7:1786-93.

55. Wei Q, Yan J, Fu B, Liu J, Zhong L, Yang Q, et al. Imp3 expression is associated with poor survival in cervical squamous cell carcinoma. Hum Pathol. 2014;45:2218-24.

56. Xu X, Ding H, Rao G, Arora S, Saclarides CP, Esparaz J. Activation of the sonic hedgehog pathway in thyroid neoplasms and its potential role in tumor cell proliferation. Endocr Relat Cancer. 2012;19: 167-79.

57. Lee SY, Han HS, Lee KY, Hwang TS, Kim JH, Sung IK, et al. Sonic hedgehog expression in gastric cancer and gastric adenoma. Oncol Rep. 2007;17:1051-5.

58. Oniscu A, James RM, Morris RG, Bader S, Malcomson RD, Harrison DJ. Expression of sonic hedgehog pathway genes is altered in colonic neoplasia. J Pathol. 2004;203:909-17.

59. Kanda S, Mitsuyasu T, Nakao Y, Kawano S, Goto Y, Matsubara R, et al. Anti-apoptotic role of the sonic hedgehog signaling pathway in the proliferation of ameloblastoma. Int J Oncol. 2013;43:695702 .

60. Che L, Yuan YH, Jia J, Ren J. Activation of sonic hedgehog signaling pathway is an independent potential prognosis predictor in human hepatocellular carcinoma patients. Chin J Cancer Res. 2012;24:323-31.

61. Blotta S, Jakubikova J, Calimeri T, Roccaro AM, Amodio N, Azab $\mathrm{AK}$, et al. Canonical and noncanonical hedgehog pathway in the pathogenesis of multiple myeloma. Blood. 2012;120:5002-13.

62. Olsen CL, Hsu PP, Glienke J, Rubanyi GM, Brooks AR. Hedgehog-interacting protein is highly expressed in endothelial cells but down-regulated during angiogenesis and in several human tumors. BMC Cancer. 2004;4:43.

63. Wang ZC, Gao J, Zi SM, Yang M, Du P, Cui L. Aberrant expression of sonic hedgehog pathway in colon cancer and melanosis coli. J Dig Dis. 2013;14:417-24.

64. Liu J, Heydeck W, Zeng H, Liu A. Dual function of suppressor of fused in hh pathway activation and mouse spinal cord patterning. Dev Biol. 2012;362:141-53.

65. Leovic D, Sabol M, Ozretic P, Musani V, Car D, Marjanovic K, et el. HH-GLI signaling pathway activity in oral and oropharyngeal squamous cell carcinoma. Head Neck. 2012;34:104-12.

66. Yauch RL, Gould SE, Scales SJ, Tang T, Tian H, Ahn CP, et al. A paracrine requirement for hedgehog signalling in cancer. Nature. 2008:455:406-10.

67. Damhofer H, Medema JP, Veenstra VL, Badea L, Popescu I, Roelink $\mathrm{H}$, et al. Assessment of the stromal contribution to sonic hedgehog-dependent pancreatic adenocarcinoma. Mol Oncol. 2013;7:1031-42.

68. Ihrler S, Zietz C, Sendelhofert A, Lang S, Blasenbreu-Vogt S, Löhrs U. A morphogenetic concept of salivary duct regeneration and metaplasia. Virchows Arch. 2002;440:519-26.

69. Yang Q, Shen SS, Zhou S, Ni J, Chen D, Wang G, et al. STAT3 activation and aberrant ligand-dependent sonic hedgehog signaling in human pulmonary adenocarcinoma. Exp Mol Pathol. 2012;93: 227-36B. 
70. Lee YS, Ha SA, Kim HJ, Shin SM, Kim HK, Kim S, et al. Minichromosome maintenance protein 3 is a candidate proliferation marker in papillary thyroid carcinoma. Exp Mol Pathol. 2010;88:138-42.

71. Li Q, Zhang Y, Zhan H, Yuan Z, Lu P, Zhan L, et al. The hedgehog signalling pathway and its prognostic impact in human gliomas. Anz J Surg. 2011;81:440-5.
72. Fan HX, Wang S, Zhao H, Liu N, Chen D, Sun M, et al. Sonic hedgehog signaling may promote invasion and metastasis of oral squamous cell carcinoma by activating MMP-9 and e-cadherin expression. Med Oncol. 2014;31:41.

73. Li H, Xiao W, Ma J, Zhang Y, Li R, Ye J, et al. Dual high expression of STAT3 and CYCLIND1 is associated with poor prognosis after curative resection of esophageal squamous cell carcinoma. Int $\mathbf{J}$ Clin Exp Pathol. 2014;7:7989-98. 